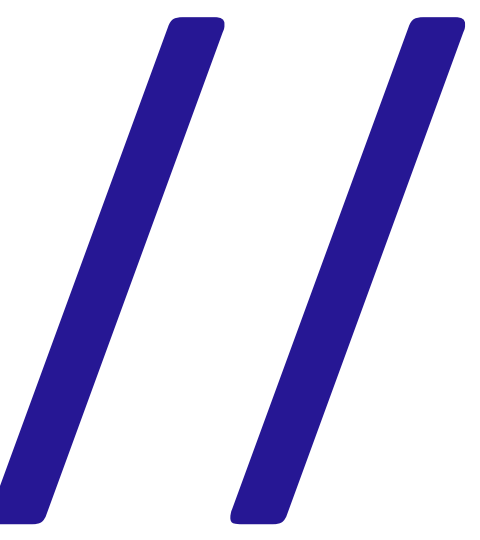

\title{
Documentário argentino em Revolución y democracia, de Javier Campo
} Argentine documentary on Revolución y democracia, by Javier Campo

Carolina Amaral de Aguiar ${ }^{1}$

${ }^{1}$ Pós-doutora em Cinema pela Escola de Comunicações e Artes da USP, com bolsa FAPESP, e em História na UNICAMP, com bolsa PNPD/ Capes. É professora do curso de graduação em História e do Programa de Pós-Graduação em História Social da Universidade Estadual de Londrina (UEL). Autora de O cinema latino-americano de Chris Marker (2015).. E-mail: amaral_carol@yahoo.com.br 
Resumo: Revolución y democracia: el cine documental argentino del exilio (1976-1984), de Javier Campo, é uma importante contribuição para entender os exílios políticos latino-americanos. Se o cinema de exílio chileno é tema bastante conhecido, o exílio cinematográfico argentino (um fenômeno de menor alcance) ainda é pouco pesquisado. Nesse sentido, o livro de Campo, lançado em 2017 em Buenos Aires, analisa os documentários políticos realizados fora do país no período em que a Argentina permaneceu sob uma ditadura, comparando os filmes feitos entre 1976 e 1984 tanto com o cinema político militante dos anos anteriores como com o cinema de transição que se consolida com a volta da democracia.

Palavras-chave: exílio; documentário argentino; cinema militante; cinema de transição.

Abstract: Revolución y democracia: el cine documental argentino del exilio (1976-1984), by Javier Campo, means an important contribution to understand the political exiles in Latin America. While Chilean cinematograph exile is a notably well-known issue, the Argentine exile (a smaller phenomenon) is still under-researched. In this way, Campo's book, released in 2017 in Buenos Aires, analyzes the political documentaries made abroad when Argentina was submitted to a dictatorship. This book compares these films premiered between 1976 and 1984 with engaged political cinema made before the coup d'état, as well as the transition cinema made after the return of democracy.

Keywords: exile; Argentine documentary; militant cinema; transition cinema. 
Os exílios políticos afetaram parte considerável do meio político e da intelectualidade nos países submetidos a ditaduras militares no Cone Sul a partir dos anos $1970^{2}$. Por outro lado, essa situação resultou numa efervescente produção cultural que acompanhou o vasto alcance geográfico da diáspora e que se dedicou a denunciar os golpes e os regimes autoritários desses países. No que se refere ao cinema, o caso de estudo mais paradigmático desse fenômeno é o chileno que, devido à sua vasta dimensão ${ }^{3}$, gerou pesquisas que deram conta das narrativas políticas construídas nos filmes e das redes de solidariedade erguidas nos anos da repressão ${ }^{4}$. Se o Chile se apresenta como um ponto fora da curva, pelo fato de seus cineastas terem conseguido um espaço de produção no exterior que não se compara ao de realizadores dos demais países da região, é necessário ressaltar a importância de se entender o exílio cultural latino-americano com mais propriedade e abrangência. Essa demanda é, em parte, atendida pelo livro de Javier Campo publicado em Buenos Aires em 2017 pela Fundación Ciccus. Campo se dedica ao ainda pouco conhecido e pesquisado exílio cinematográfico argentino, atendo-se especificamente ao documentário político produzido entre 1976-1984, recorte delimitado pelo golpe de Estado e pela consolidação da volta da democracia.

Apesar de indicar no título que o livro se ocupa do cinema argentino de exílio, o escopo temporal e a problemática de Javier Campo são bastante mais amplos. Organizada em quatro capítulos, a obra analisa o "documentário político" - ou seja, aquele que faz menção a "partidos ou movimentos políticos ou personagens da política nacional e/ou [que] exponha tópicos associáveis a questões do debate público argentino em imagens [...] ou relatos" (CAMPO, 2017, p. 17, tradução nossa) - entre 1968 e 1989, embora dedique menos fôlego aos períodos anterior e posterior à ditadura. A ampliação do recorte temporal se justifica pelo objetivo de estabelecer persistências e rupturas tanto em relação às temáticas dos filmes como às escolhas estéticas adotadas. Assim, o capítulo dois, "Antes y después de la dictadura y el exilio", e o capítulo quatro, "Conclusión: valor del cine del exilio", dão conta desse viés metodológico comparativo e da tentativa de buscar o que seria a especificidade do documentário político feito pelos exilados.

\footnotetext{
${ }^{2}$ Segundo Javier Campo (2017), o exílio político que se seguiu aos golpes de Estado afetou cerca de $1 \%$ a $2 \%$ da população argentina e chilena, atingindo cifras ainda maiores no caso do Uruguai, onde estima-se que em torno de $10 \%$ da população tenha se exilado.

${ }^{3}$ Em seu livro publicado nos anos 1980, Jacqueline Mouesca (1988) havia encontrado 178 películas feitas no exílio por realizadores chilenos.

${ }^{4}$ Pode-se citar como exemplos os trabalhos pioneiros de Valjalo e Pick (1984) e Mouesca (1988).
} 
O primeiro capítulo, "De la espada a la palabra. El marco sociopolítico”, procura justamente traçar um debate sobre a condição do exílio e as mudanças de discurso operadas nesse contexto, que aparecerão nos filmes analisados adiante. Dominando com primazia a discussão historiográfica argentina, Campo procura mostrar a tensão entre um vocabulário marxista revolucionário vigoroso entre 1968 e 1976, não dedicado à pauta democrática, e uma revalorização da democracia como bandeira que vai gradativamente ganhando espaço durante o exílio, em consonância com o discurso internacional dos direitos humanos. A transformação das "narrativas revolucionárias" em "narrativas humanitárias", tendência que não se restringe ao meio cinematográfico, pode ser verificada no documentário político estudado pelo autor. Dessa forma, a análise da produção audiovisual "revolucionária” pré-1976 (como os filmes dos grupos militantes Cine Liberación, Cine de la Base, Realizadores de Mayo, entre outros) é contraposta ao estudo das películas feitas no período de transição democrática; estas últimas voltadas às denúncias dos sequestros, desaparecimentos e mortes, para as quais o testemunho terá um grande peso narrativo.

O documentário de exílio - situado entre esses dois períodos que, como já foi dito, são estudados no capítulo dois - é o tema central do capítulo três, "La resistencia: el documental político argentino entre 1976 y 1984". Neste capítulo está a maior contribuição do livro, que é o mapeamento e a análise da produção de documentários políticos do exílio argentino. Javier Campo localiza onze títulos realizados por exilados, corpus a partir do qual privilegia a análise fílmica de Las AAA son las tres armas, (As AAA são as três armas, 1977), de Jorge Denti; Persistir es vencer (Persistir é vencer, 1978), de Jorge Giannoni e Álvaro Melián; Resistir (1978), de Julián Calinki; e Tango (1979), de Jorge Cedrón. O autor opta por uma metodologia bastante formalista e comparatista em relação aos filmes analisados. Para chegar às conclusões, indica que dividiu todas as sequências de todos os documentários se atentando para:

\begin{abstract}
imagem e som próprios, imagem alheia e som próprio, imagem própria e som alheio e imagem e som alheios. "Próprio" significará aqui gerado para o filme, de fatura própria do realizador; enquanto "alheio" quererá dizer imagens ou sons tomados de outros filmes, ou ainda de publicações gráficas, fotografias, música ou programas de rádio e televisão. (CAMPO, 2017, p. 20, tradução nossa)
\end{abstract}

O autor expõe algumas das macroquestões que guiaram a análise formal: “Como estão elaborados esses filmes documentários políticos? De que 
maneira apresentam seus discursos políticos e o que dizem os mesmos? É possível vincular formas e estruturas cinematográficas com tendências ideológicas?" (CAMPO, 2017, p. 70, tradução nossa). Campo identifica nesse corpus do exílio, inicialmente, continuidades em relação ao "tom combativo" da produção militante de antes do golpe. Porém, gradativamente percebe-se no período entre 1976 e 1984, segundo o autor, a diminuição na intensidade do discurso revolucionário e um maior espaço para narrativas democráticas. Essa migração se reflete, por exemplo, no uso da voz over e dos testemunhos, que parecem abrir-se de uma perspectiva única para a busca por uma pluralidade coral. Um título emblemático desse processo foi Esta voz... entre muchas (Esta voz... entre muitas, 1979), realizado no México pelo argentino Humberto Ríos, que foi o primeiro documentário que deu voz diretamente aos familiares de desaparecidos e de assassinados.

O quarto capítulo, “Conclusión: valor del cine del exilio”, retoma a ênfase na democracia e nos direitos humanos que ganha espaço nos filmes do exílio quando comparados com aqueles feitos antes do golpe e depois do fim da ditadura:

Uma das características desses filmes que surgem das hipóteses é que o primeiro grupo deles, os realizados entre 1976 e 1978 , sustentam um discurso de narrativa revolucionária, similar aos do período anterior ao golpe de Estado. Enquanto os realizados posteriormente exaltam os valores da democracia republicana e denunciam a ditadura desde narrativas humanitárias. Embora essa distinção seja em princípio corroborada por esta análise, pode-se dizer que no interior desses dois grupos de documentários há alguns matizes, não todos são chamados completamente fechados à luta armada ou à defesa republicana dos Direitos Humanos. (CAMPO, 2017, p. 155, tradução nossa)

Dessa maneira, a tese do autor é formulada a partir de uma articulação entre a análise fílmica e os discursos históricos-políticos propostos pelas obras. O estudo dos documentários revela que, segundo o autor, o cinema realizado na segunda fase do exílio, entre 1979 e 1984, introduz novas características estéticas que produzem uma perspectiva mais aberta, em consonância com o caráter humanitário que os filmes assumem em seu discurso. Campo propõe que se pode localizar uma tendência que articula "perspectiva formal" e "revolução", como um polo, e "perspectiva aberta" e "democracia”, como outro.

Retomando a comparação com o caso do cinema de exílio chileno, proposta na introdução desta resenha, o livro de Javier Campo leva à formulação da pergunta se é possível falar de um "cinema de exílio argentino", considerado como um fenômeno 
cinematográfico e histórico semelhante ao do país vizinho. O autor de Revolución y democracia declara que esses documentários feitos por argentinos após o golpe de Estado tiveram uma circulação muito reduzida. Revela ainda que havia pouco contato entre os diretores, o que coloca em dúvida a existência de uma rede transnacional. Esse caráter fragmentário é justificado no livro pela dispersão geográfica e pelas diferenças ideológicas entre os grupos de realizadores. Sem dúvida, essas razões, além de plausíveis, colocam em evidência mais um mérito do trabalho de Campo, que é o de dar corpo a uma gama de documentários que ainda não haviam sido tratados como um conjunto. No entanto, o vigoroso cinema de exílio chileno talvez possa indicar outras dificuldades enfrentadas pelos argentinos para produzir no exterior. Ao contrário do Chile, cujo golpe derrubou de forma trágica e cinematográfica um governo que tinha grande apoio das sociais-democracias e das esquerdas, a escalada da violência no contexto pré-1976 na Argentina tornava a compreensão internacional desse processo histórico mais complexa e difícil. Para completar, o peronismo e suas diferentes formas de apresentação política podem ter sido um aspecto que dificultou a recepção aos exilados vindos desse país. Essas hipóteses, apresentadas aqui de modo rápido e pensadas a partir do livro de Javier Campo, servem para apontar o quanto ainda se pode avançar no estudo das produções culturais - e, particularmente, das audiovisuais do exílio. Nesse sentido, a publicação de Revolución y democracia deve se consolidar como leitura incontornável para quem trabalha com o tema e inspiradora de novas pesquisas.

\section{Referências}

CAMPO, J. Revolución y democracia: el cine documental argentino del exílio (1976-1984). Buenos Aires: Fundación Ciccus, 2017.

MOUESCA, J. Plano secuencia de la memoria de Chile: veinticinco años de cine chileno (1960-1985). Madri: Ediciones del Litoral, 1988.

VALJALO, D.; PICK, Z. M. 10 años de cine chileno: 1973-1983. Los Angeles: Ediciones de la Frontera, 1984.

\section{Referências audiovisuais}

ESTA voz... entre muchas (Esta voz... entre muitas). Humberto Ríos, México, 1979.

LAS AAA son las tres armas (As AAA são as três armas). Jorge Denti, Peru, 1977.

PERSISTIR es vencer (Persistir é vencer). Jorge Giannoni e Alvaro Melián, Itália, 1978. 
RESISTIR. Julián Calinki, França/Itália, 1978.

TANGO. Jorge Cedrón, França, 1979.

submetido em: 13 jun. 2019 | aprovado em 1 jul. 2019 